\title{
LA CUESTIÓN DE LA CONSERVACIÓN DEL PATRIMONIO MUEBLE DE SAN FRANCISCO
}

Israel Zambrano $B$.

UNESCO - Ecuador

\section{Resumen}

Se realizó un análisis organoléptico obra por obra, el cual dio como conclusión que la iglesia de San Francisco no contaba con un plan de conservación. La mayoría del deterioro se debe al factor humano por manipulación no adecuada; ello conlleva a una conservación preventiva, actualización y culminación del inventario, implementación de equipamientos, evaluación de condiciones ambientales y luminarias, conservación de la colección de la biblioteca, así como pintura y material arqueológico en las que se incluyen diferentes capillas. La restauración además presenta una colaboración hacia la comunidad.

Palabras clave: organoléptico, San Francisco, evaluación, colección, biblioteca, condiciones, ambientales, luminarias.

\begin{abstract}
The organoleptic analysis that was performed work by work, brought to the conclusion that the church of Saint Francis did not have a conservation plan, and most of the deterioration was due to the human factor by improper handling; This led to its preventive conservation, its inventory update and completion, equipment implementation, evaluation of the environmental conditions and lighting, conservation of the library collection as well as of the paintings and the archaeological material, in which different chapels were included. The restauration also stablishes a partnership with the community.

Keywords: organoleptic, church of Saint Francis, evaluation, collection, library, environmental, luminaires.
\end{abstract}




\section{Antecedentes}

San Francisco con su convento, iglesias y la plaza conforma uno de los conjuntos arquitectónicos de mayor relevancia a nivel internacional, al interior guarda un sinnúmeros de obras artísticas, historia y tradiciones. En el paso del tiempo muchos factores han ido afectando a la conservación de los bienes muebles, especialmente los de carácter antrópico y a los que se han sumado las catástrofes naturales, en el caso de Quito los terremotos han sido una constante.

Al día de hoy nos han llegado una colección de más de 3000 obras de carácter artístico, cerca de 20000 volúmenes y miles de documentos correspondientes a la biblioteca y archivo provincial, respectivamente. Su conservación ha demandado acciones constantes tanto de la comunidad religiosa como de instituciones nacionales como internacionales. En el marco del Plan de Gestión del Conjunto Conventual de San Francisco, se desarrolló durante el 2013 el respectivo diagnóstico de la colección de bienes muebles y la definición de líneas de acción en base a las necesidades y prioridades visibilizadas.

Estos insumos permitieron, ir delineando el Plan de Gestión, el cual, en su fase de ejecución, abordó varios proyectos de conservación e impulso varias ideas de difusión, que se consolidaron, en el caso del patrimonio mueble, en la campaña "Pinto por el patrimonio de San Francisco", la cual se basaba en la ayuda de voluntarios para permitir un acercamiento del público al patrimonio y generación de vínculos con el mismo.

\section{Introducción}

El conjunto monumental de San Francisco desde los primeros años de su fundación, ha tenido entre sus paredes un gran número de obras de arte religioso, documentos, libros y últimamente material arqueológico, llegando a nosotros una colección que supera las $3398^{188}$ obras. Esta gran acumulación de obras, responde, en gran medida, a la Escuela San Andrés, fundada en 1551 por Fray Francisco de Morales en honor a Don Andrés Hurtado de Mendoza, Marqués de Cañete y tercer virrey del Perú (Navarro, 2006), que funcionó en el convento. En la misma, se promulgó la enseñanza de las bellas artes: pintura, escultura y música (Moreno, 1998).

Estos bienes muebles de carácter patrimonial están realizados en una gran variedad de soportes, entre los que se puede enumerar: cuero, mampostería, madera, textil, metal, piedra, cerámica, papel, entre otros. Su tipología es diversa teniendo entre las principales: decoración mural, pintura, escultura, documentos, carpintería, retablos, mobiliario, metalurgia, textil, lapidaria, etc. La diversidad tipológica, así como el soporte de cada obra, ha hecho que tengan un comportamiento distinto frente a los diferentes factores de deterioro. Además, las condiciones de almacenaje, de exposición y el lugar que los alberga, influyen considerablemente en

188 Dato tomado del Sistema ABACO el 23 de enero de 2015, se contabilizan solo las fichas de inventario de bienes muebles. Este dato no incluye la colección de la biblioteca, los documentos del archivo provincial y el material arqueológico. 
su estado de conservación. Variables que debieron ser consideradas al momento de abordar el diagnóstico de la colección, en marco del Plan de Gestión del Conjunto Conventual de San Francisco ${ }^{189}$.

El factor antrópico, definido como uno de los principales agentes en el deterioro de las obras, requería pensar a las acciones de intervención no aisladas de la interacción con la gente. Un taller abierto y visitable en determinadas horas, que contase sobre el proceso de conservación y restauración a los visitantes, fue una de las herramientas usadas. A esta iniciativa luego se sumó el empleo de la museología para presentar una exposición que recoja la manufactura, conservación y simbología de las obras expuestas.

Retos que se han debido ir tomando en las diferentes fases del plan de gestión, y pensados desde la necesidad de

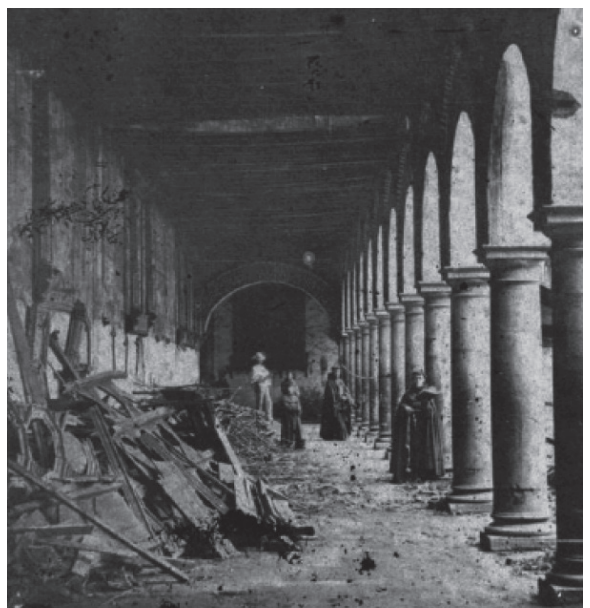

Foto 1. Claustro principal de San Francisco, detalle de los deterioros producidos por el terremoto de 1868. Fuente: Archivo Nacional de Fotografía (INPC, 2015).

permitir la conservación, difusión y empoderamiento del patrimonio cultural, en este caso: mueble.

\section{Diagnóstico de la colección de bienes muebles ${ }^{190}$}

Con base en la información preexistente sobre la colección de bienes muebles y sus características particulares se definió una metodología para el diagnóstico, la cual constituyó un análisis organoléptico respaldado por las fichas de inventario y registro de bienes muebles del Sistema ABACO del Instituto Nacional de Patrimonio Cultural (INPC) ${ }^{191}$, las fichas de prelación levantadas en el 2005 por Galeotti, M. en el marco del "Estudio Integral de los Bienes Muebles de la Iglesia de San Francisco" y las fichas de evaluación de riesgo en museos propuestas en el 2006 por Paula Matiz y Ángela Ovalle en su libro "Conservación Preventiva en Museos: evaluación de riesgos”. El uso de estas fichas se complementó con el monitoreo de la humedad relativa y temperatura, y la medición puntual de la iluminancia, en varias áreas. En la ejecución del diagnóstico participaron pasantes de la Universidad Tecnológica Equinoccial (UTE) de la Carrera de Restauración y Museología, quienes recibieron una capacitación previa por parte del INPC,

189 El cual está liderado por la Oficina de UNESCO-Quito y fue elaborado gracias al aporte de la Cooperación Italiana al Desarrollo. El Comité Ejecutivo del Plan, entidad encargada de llevar a cabo las acciones del mismo, cuenta con la participación del Instituto Nacional de Patrimonio Cultural (INPC), el Municipio del Distrito Metropolitano de Quito a través del Instituto Metropolitanos de Patrimonio (IMP), Quito Turismo y la Comunidad Franciscana.

190 Extracto tomado del "Diagnóstico del estado de conservación mueble", desarrollado como parte del "Plan de Gestión para el Conjunto Conventual de San Francisco de Quito", por el autor (UNESCO, 2013).

191 Ingresadas al sistema hasta 11 de marzo de 2013. 
en temas referentes a conservación preventiva, bienes muebles, inventario y el Sistema $\mathrm{ABACO}^{192}$. El trabajo en campo se desarrolló desde 09 de abril al 02 de septiembre de 2013.

\section{Conclusiones}

De este este análisis organoléptico realizado obra por obra, en las áreas en que las obras están expuestas o permiten una accesibilidad a las mismas, y en áreas de gran concentración de obras en base a una evaluación general, se desprendieron las siguientes conclusiones:

El Convento de San de Francisco no contaba con un Plan de Conservación Preventiva, ni se ejecutaban acciones periódicas de conservación preventiva que permitiesen minimizar los efectos de los factores de deterioro. Es por esto que el polvo y otros contaminantes, en diferentes grados, estaban presentes en la totalidad de la colección.

Uno de los principales factores de deterioro era el humano, ya sea por una utilización no cuidadosa de los bienes muebles que aún se encuentran en uso religioso, como era el caso de los albergados en la iglesia y capilla de Cantuña. O por acciones vandálicas que habían producido entre otros deterioros: fracturas, desprendimiento de estratos, marcas, rayones y quemaduras.

El registro e inventario del Sistema Abaco del INPC, correspondiente al Convento de San Francisco se encontraba desactualizado. En algunos casos la información de las fichas no está completa y aún quedaban bienes muebles por ser inventariados.

Las obras albergadas en la bodega No 1 de la Sacristía y las del antiguo Noviciado, se encontraban en un proceso de continuo deterioro provocado principalmente por las condiciones no técnicas de su almacenaje, sus características intrínsecas y los factores ambiental y biológico.

Las áreas que requerían una intervención emergente y/o traslado de las obras que contienen eran: bodega No 1 de la Sacristía, bodegas del antiguo Noviciado, biblioteca y la Capilla de la Virgen del Pilar.

El museo, y el convento en general, no contaban con personal técnico en el área de conservación. Esto había llevado a que la manipulación de las obras no se haga de manera técnica, algo que se ha visto reflejado en los golpes, rayaduras, roturas, entre otros deterioros que tenían las bienes muebles.

La reserva de pintura y mobiliario existentes, requerían que se finalice su acondicionamiento técnico y que se implemente nuevas áreas de reserva, dada la gran cantidad de obras que se encontraban almacenadas en áreas y condiciones no idóneas.

La biblioteca del convento se encontraba saturada, la cantidad de libros que podía albergar en su espacio físico había sido rebasada, lo cual había llevado a que cerca de 500 libros estén apilados en el piso, en proceso de constante deterioro.

192 La metodología usada para el diagnóstico se detalla en el "Plan de Gestión para el Conjunto Conventual de San Francisco de Quito", UNESCO 2013. 


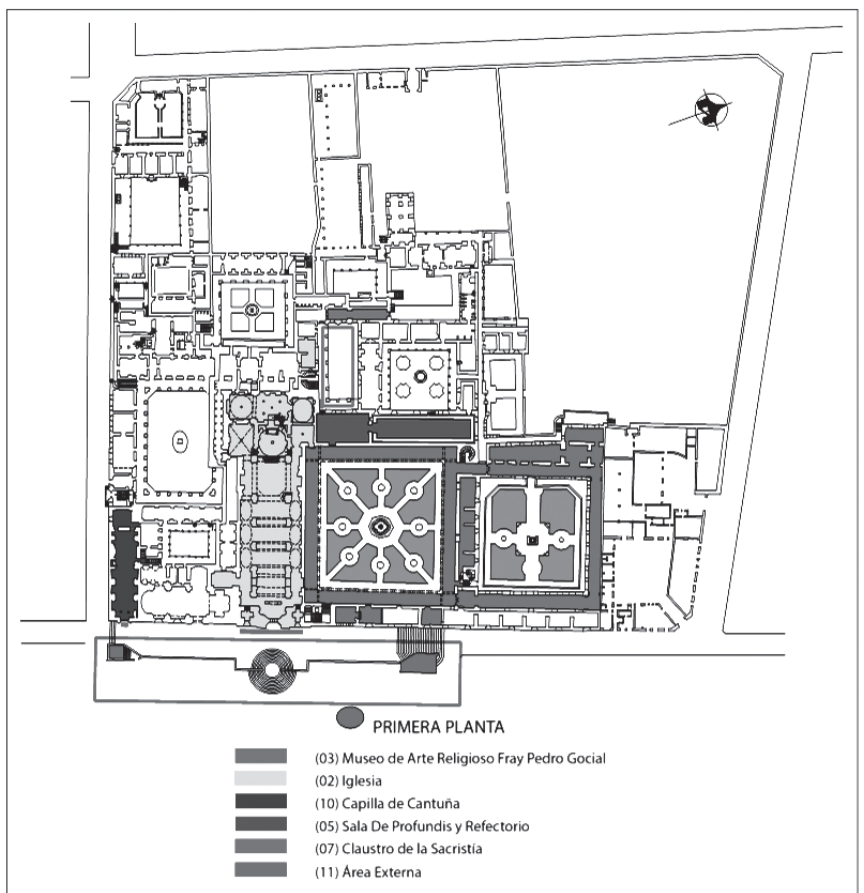

Ilustración 1. Ubicación de zonas con bienes muebles, se colorean completamente sólo las áreas con obras. Fuente: elaboración autor en base al plano digital del Proyecto Rehabilitación Integral Iglesia y Convento de San Francisco. FONSAL

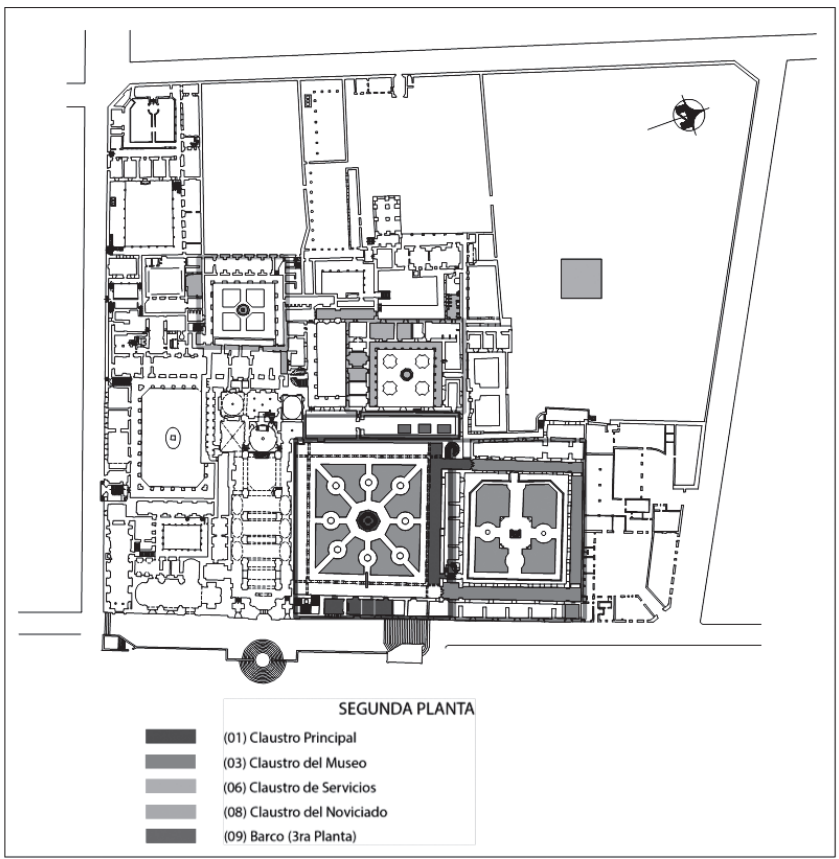

Ilustración 2. Ubicación de zonas con bienes muebles, se colorean completamente sólo las áreas con obras. Fuente: elaboración autor en base al plano digital del Proyecto Rehabilitación Integral Iglesia y Convento de San Francisco. FONSAL 


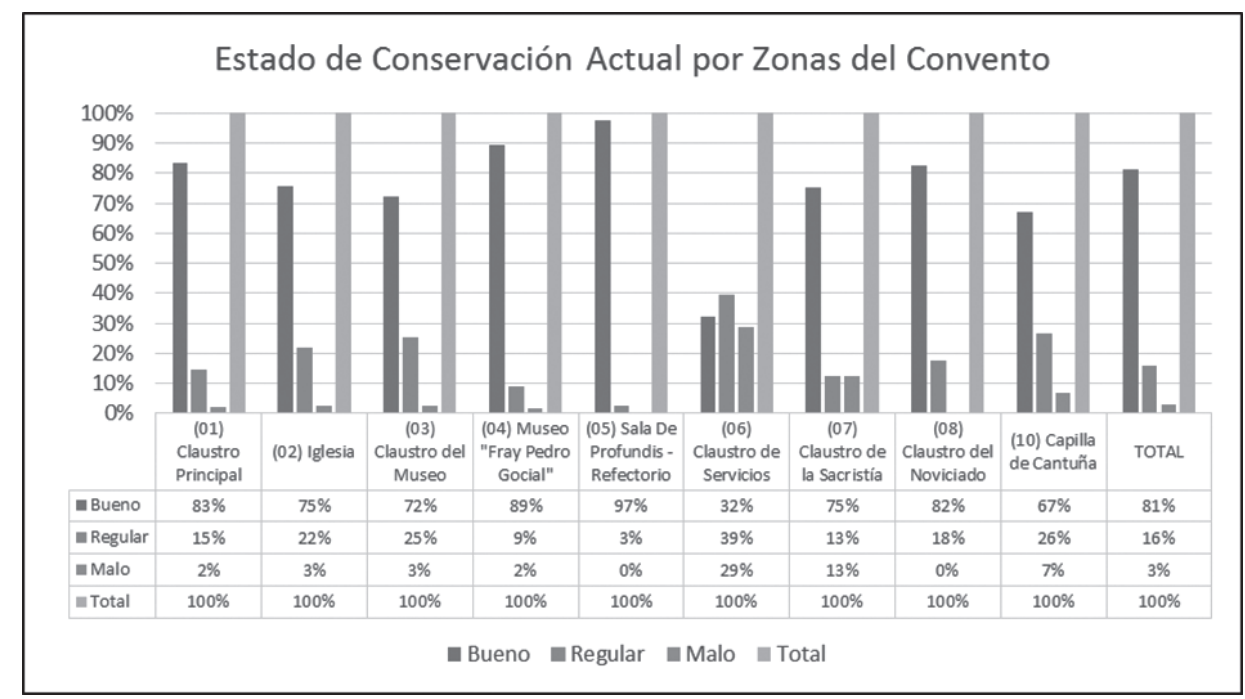

Gráfico 1. Estado de conservación actual. Fuente: Elaboración autor en base a la actualización del componente de conservación de las fichas de registro e inventario del Sistema ABACO del INPC

\section{Líneas de acción}

Partiendo del diagnóstico realizado y en el marco de un plan de gestión integral y sustentable, las líneas de acción, con sus respectivos proyectos de intervención, que se propusieron estuvieron planteadas para tengan, después de su ejecución, el seguimiento necesario y un mantenimiento constante, como parte de un plan de conservación preventiva. Es por esto que se propuso la implementación de un taller de conservación a corto plazo. Este taller, dotado de los elementos técnicos y de personal capacitado, deberá con el tiempo y con la consolidación del Comité de Gestión, pasar a ser una unidad de conservación, encargada de monitorear, conservar, restaurar, investigar y difundir el patrimonio mueble del Convento de San Francisco.

Las acciones a tomarse se encontraban enmarcadas en cuatro líneas de acción: Conservación Preventiva, Conservación, Conservación-Restauración y Museología-Museografía.

\section{Conservación preventiva}

En esta línea de acción se han considerado los trabajos que buscan "identificar, evaluar, detectar y controlar los riesgos de deterioro de los objetos (y) colecciones" (IPCE, 2011), con el objetivo de minimizar la afectación de las obras. La consolidación de los proyectos planteados en esta línea, permitirá en el mediano y largo plazo, reducir los deterioros en las obras y planificar nuevas intervenciones e investigaciones.

- Actualización y culminación del inventario, implementación de una herramienta digital para el manejo interno de las fichas de bienes muebles y definición de acciones de conservación preventiva 
Dada la importancia de contar con un inventario actualizado, completo y operativo para la gestión de la colección, es necesario culminar con el mismo cuanto antes. Esto permitirá identificar, organizar, cuantificar, localizar y conservar la información de las intervenciones, de los movimientos y prestamos de los objetos. Para esta operatividad se propone que se cree una aplicación compatible con el Sistema ABACO, que permita el ingreso de estos datos y estos sean manejados a nivel local. Propendiendo con esto, a no crear una duplicidad de inventarios y mantener la información del ABACO actualizada.

La conservación preventiva, considerada como una forma de prevenir deterioros en los bienes muebles, al investigar y analizar los riesgos, al definir criterios y métodos de trabajo, al coordinar las actuaciones, al capacitar y permitir el acceso a la información, y propender a la optimización de los recursos (IPCE, 2011), debe ser una pieza clave en un plan de gestión que busca la conservación del patrimonio a largo plazo.

Con estos antecedentes se propone la elaboración e implementación de acciones de conservación preventiva, que se convierta en el instrumento guía para la actuación del personal del taller de conservación. Esta propuesta deberá articularse con el "Plan integral de gestión de riesgos", propuesto desde el área de bienes inmuebles, y llevarlo a la especificidad de bienes muebles.

\section{- Implementación de equipamientos para las reservas de BB.MM.}

Dada la gran cantidad de obras que se encuentran embodegadas en espacios improvisados carentes de las condiciones técnicas, en cuanto al mobiliario, a la disposición de los objetos, a las condiciones ambientales y al mantenimiento, es necesario adecuar los espacios que mejores condiciones presten a "los materiales técnicas, formas, formatos y pesos de los objetos de la colección, a sus requerimientos y necesidades de conservación” (Matiz \& Ovalle, 2006).

Se ha propuesto que las reservas se ubiquen en el ala este de la segunda planta del claustro principal, por ser al momento el mejor lugar para emplazarlas y al haber ya una celda (C3) adecuada parcialmente como reserva de pintura. A adicionalmente se ha considerado la implementación de otras reservas en el antiguo Noviciado (ver Ilustración 3), cuartos que actualmente albergan una gran cantidad de bienes muebles en condiciones inadecuadas y de constante deterioro.

Esta acción es complementaria a la propuesta desde el área de bienes inmuebles y se limita a la dotación del mobiliario necesario, el cual deberá ser definido en base al tipo de colección que albergará, y a los elementos de protección para la ubicación de los bienes en la unidades de almacenaje. El mobiliario deberá ser construido con materiales seguros para "la conservación, es decir, inertes y estables física y químicamente... se deben usar materiales incombustibles, impermeables y libres de ácido, y evitar... aquellos que liberen sustancias contaminantes" (Matiz \& Ovalle, 2006), es recomendable el uso de mobiliario metálico protegido contra la oxidación.

- Evaluación de las condiciones ambientales y de iluminancia, y su afectación en las obras e implementación de los correctivos necesarios 
En el fase de diagnóstico se realizó un monitoreo de varias áreas, considerándose para aquello la concentración de obras, la escasa ventilación o el ingreso constante de corrientes de aire, la iluminación natural y artificial que tenían. Estos factores pueden alterar la humedad y temperatura, llegando a niveles propicios para la proliferación de actividad biológica o produciendo afectaciones directas sobre las obras. Sin embargo se requiere de un monitoreo en extenso que permita tomar los correctivos necesarios de ser el caso, propendiendo con esto a la conservación preventiva.

Es así que se ha considerado realizar esta acción en las áreas abiertas, junto a vegetación y por las características y el volumen de la colección. Los espacios a monitorearse son el claustro principal en su primera planta en los corredores, la segunda planta corredor norte, el museo, la biblioteca, el archivo y las futuras áreas de reserva (ver Ilustración 4).

\section{Conservación}

En esta línea de acción se busca estabilizar a los objetos que se encuentran en proceso de deterioro, actuando sobre el entorno y la obra, así como tender a una conservación futura de la colección en condiciones técnicas.

\section{- Conservación de la colección del Museo de Arte Religioso "Fray Pedro Gocial"}

El 95\% de la colección del museo se encuentra en un estado de conservación bueno, sin embargo carece de conservación preventiva, lo que ha provocado la acumulación de polvo ligero y sedimentado, aparición de focos de infección de xilófagos y el deterioro de obras más sensibles como textiles y libros.

Es por esto necesario realizar su conservación y determinar qué obras pueden seguir en exposición o deben ser sustituidas por su sensibilidad y estado de conservación. Además de la dotación de los elementos de protección necesarios para el anclaje o exhibición de las obras.

- Conservación y traslado de los bienes muebles de la bodega 1 de la Sacristía y los textiles de la Sacristía de la Capilla de Cantuña

El 75\% de las obras almacenas en esta bodega son textiles, los cuales se encuentran en su mayoría dispuestos en forma vertical, apilados y doblados en contendores de tamaño inferior al requerido por las obras. En la misma área se guarda un conjunto elementos litúrgicos de plata y bronce los cuales presentan oxidación y deterioro por manipulación.

Esta bodega al no prestar las condiciones técnicas para almacenar estas obras, al tener un espacio reducido que no permite una circulación adecuada, al carecer de una buena ventilación y al encontrase junto al cementerio, es necesaria y prioritaria la reubicación de las obras que alberga, así como su conservación y almacenaje técnico en una de las áreas asignadas como reserva o momentáneamente a otra área con mejores condiciones para la conservación.

Los textiles religiosos almacenados en la Sacristía de la Capilla de Cantuña, que se encuentren inventariados también serán conservados y trasladados al lugar en el que se depositen los otros. 


\section{- Estudio e implementación de un taller de conservación}

Como parte fundamental de la conservación de la colección a largo plazo, es necesario dotar al convento de un taller de conservación con el personal capacitado y con los recursos técnicos necesarios para ejecutar su trabajo.

El personal técnico con el que cuente el taller deberá, con base en el plan de conservación preventivo, ejecutar las acciones pertinentes para la buena conservación de las obras, realizar intervenciones de conservación-restauración, administrar el inventario y proponer los proyectos de intervención que se requieran ejecutar y dar seguimiento a los mismos.

\section{- Conservación de la colección de la Biblioteca y de los documentos del Archivo Provincial}

La biblioteca actualmente se encuentra saturada en su capacidad, es así que una cantidad significativa de libros reposan apilados en el suelo, dificultando la circulación y provocando deformaciones por compresión en los libros menos robustos.

La biblioteca no es de uso público y su acceso está restringido a la persona a cargo de su administración, lo que ha llevado a una gran acumulación de polvo sobre los libros y las estanterías. Para la ventilación del espacio se dejan las ventanas abiertas por tiempos prolongados, permitiéndose el ingreso de insectos, arácnidos y aves al interior. Encontrándose en el caso de los insectos y arácnidos sus cadáveres y en el caso de las aves sus excrementos.

Dado el continuo deterioro al cual están sometidos los libros es necesario realizar su conservación y almacenaje adecuado definiéndose hasta que año se conservaran los libros en esta biblioteca y trasladándose el resto de libros a otra área. Ya que solo con una buena distribución del espacio y una buena organización de los libros en las estanterías se podrá asegurar su conservación y permitirse las acciones de conservación preventiva.

En el caso del archivo las condiciones de conservación son mejores, ya que se los documentos están ubicados en contenedores y colocados en estanterías metálicas. Con esta intervención se quiere eliminar los elementos metálicos e hilos que sujetan las hojas, determinar si los elementos usados para el almacenaje son $\mathrm{pH}$ neutro, o requieren ser cambiados. Los documentos fotográficos deben ser almacenados adecuadamente y en contenedores, ya que al momento se ubican en fundas plásticas y el resto de fotos en un cajón.

- Conservación de mobiliario y conservación y clasificación de fragmentos de mobiliario y retablos

En las bodegas ubicadas en el antiguo Noviciado, se encuentran una gran cantidad de fragmentos de molduras, paneles y ornamentos en madera presumiblemente de la antigua Capilla de San Buenaventura. Las condiciones de apilamiento junto al muro o en cajas de cartón favorecen su deterioro por compresión, encontrándose varias piezas rotas o en proceso de fractura. El ataque de xilófagos en la actualidad o en el pasado es constante en todas las piezas y la mala distribución en los espacios imposibilita cualquier actividad de limpieza, teniéndose en la mayoría de los casos que mover los objetos para alcanzar a otros. 
Las actividades de conservación preventiva son nulas en estas áreas y la existencia de una alfombra en una de las reservas favorece la acumulación de grandes cantidades de polvo. Dadas estas condiciones se propone la conservación de estos elementos y su clasificación y registró gráfico de acuerdo a sus características morfológicas con el fin de tener una idea de qué estructuras formaban parte. Adicionalmente a las obras de estas reservas se considera la intervención de varios fragmentos ubicados en la bodega de la cocina del claustro de la Sacristía. Las obras ya intervenidas serán almacenadas técnicamente en un área habilitada como reserva.

- Conservación de pintura y escultura, y conservación y clasificación del material arqueológico

Adjunto a los fragmentos de madera, se encuentran almacenadas esculturas, pinturas y material arqueológico, parte del material óseo producto de excavaciones en el convento se encuentra en fundas de basura y muchos de los huesos están desperdigados sobre otras obras. El deterioro es constante por lo que se hace necesario una intervención emergente que estabilice las condiciones de conservación.

Adicionalmente se debe realizar una clasificación morfológica del material arqueológico, que permita una adecuada conservación y un panorama de los elementos que se tiene embodegados, ya que se considera como posible acción a futuro, la implementación de una sala arqueológica en el museo.

La intervención comprende las obras embodegadas en el antiguo Noviciado (ver Ilustración 6), en la bodega de la cocina del claustro de la Sacristía y el material arqueológico de la celda 2 de la segunda planta del claustro principal. Las obras ya conservadas serán almacenadas técnicamente en un área habilitada como reserva.

\section{Conservación - Restauración}

Las intervenciones que comprenden esta línea de acción y a la de conservación deben estar apegadas al máximo respeto a la obra y deberán ser ejecutados de acuerdo a la metodología de trabajo que establezcan los estudios pertinentes.

\section{- Conservación y restauración de las pinturas de la "Vida de San Francisco"}

Las obras correspondientes a la vida de San Francisco ubicadas en claustro principal en los corredores de la primera planta, en la sala De Profundis y en el corredor y bodegas del antiguo Noviciado, por su importancia y su estado de conservación, que va de regular a malo en la mayoría de los casos, requieren una intervención que reduzca o elimine el proceso de degradación y una intervención de restauración que restituya la unidad potencial de la obra.

En el caso de las obras ubicadas en espacios abiertos, será el resultado que arroje el proyecto de evaluación de las condiciones ambientales y de iluminación, el que defina si estas obras deben ser colocadas en otra área o que se tome alguna acción para impedir que la variabilidad ambiental y de iluminación de estos espacios puedan deteriorar las obras. 
- Conservación y restauración de la pinturas de la "Vida de Jesús", cuadro genealógico de la Orden Franciscana y retablos y cielos rasos del claustro principal

Esta intervención de carácter similar a la anterior comprende las obras ubicadas en el claustro de la Sacristía en la bodega de la cocina, en la segunda planta: corredor y bodegas del antiguo Noviciado y en la celda 2 de la segunda planta del claustro principal.

- Conservación y restauración de los objetos utilitarios y equipamiento industrial de la Cervecería

Al considerarse la inclusión de la sala temática de la cervecería franciscana en el Museo "Fray Pedro Gocial", como un proyecto a corto y mediano plazo, se plantea la intervención de conservación y restauración de los elementos que pertenecían a la cervecería y se encuentran ubicados en el claustro de la Sacristía en la bodega de la cocina, en la cervecería y galpón junto al área de servicios. Será el guion museográfico el que definirá que elementos serán considerados para la exposición, los que no sean tomados en cuenta serán ubicados en una reserva.

\section{- Conservación y restauración integral de la capilla de la Virgen del Pilar}

Esta acción se enmarca en el Proyecto Rehabilitación Integral Iglesia y Convento de San Francisco elaborado por ex-Fonsal en el año 2010 y tiene como base el "Estudio Integral de los Bienes Muebles de la Iglesia de San Francisco", realizado por M. Galeotti Fiori en el año 2005. Al igual que en el estudio anterior, se establece en este la intervención de esta capilla como emergente.

Las intervenciones a realizarse deben ser coordinadas con las de arquitectura, ya que se debe solucionar el problema de humedad que afecta a los muros y a los elementos de madera anclados a los mismos.

Las obras a ejecutarse comprenden los retablos, esculturas, pinturas y el mobiliario perteneciente a la capilla. La intervención en pintura mural no ha sido considerada en este proyecto ya que ha sido incluida en el componente de bienes inmuebles.

- Conservación y restauración integral de la Sacristía

Esta intervención de carácter similar a la anterior comprende los retablos, esculturas, pinturas y el mobiliario que perteneciente a la capilla.

- Conservación y restauración integral de la iglesia: transepto, naves central y laterales, sotocoro, nártex y capilla de Jesús del Gran Poder

Esta acción que se complementa con la planteada desde el área de arquitectura, comprende la intervención en bienes muebles de las áreas que aún no han sido intervenidas. Siendo estas: transepto, naves central y laterales, sotocoro, nártex y Capilla de Jesús del Gran Poder. La mayoría de esculturas fueron ya intervenidas en un proyecto anterior en el año 2011, por lo que su intervención se limitará a la conservación y en caso de las obras no intervenidas se llegará a la restauración. 
Esta intervención deberá ser planteada en fases de acuerdo a las características de cada sector, y comprende: retablos, esculturas, pinturas y mobiliario perteneciente a las diferentes áreas de la iglesia. La intervención en pintura mural no ha sido considerada en este proyecto ya que ha sido incluida en el componente de bienes inmuebles.

\section{Museología - Museografía}

Esta línea de actuación comprende la parte museológica-museográfica, con la cual se busca la revitalización del museo y la implementación de medidas de control y seguridad que permitan la conservación de los elementos de la colección.

- Guión museológico, diseño museográfico e implementación de la sala temática de la Cervecería Franciscana

Como una forma de integrar al museo un espacio que hable sobre una de las actividades de la vida conventual, se ha propuesto la implementación de la sala temática de la cervecería franciscana.

Para lo cual se deberá realizar la respectiva investigación histórica, el guión museológico y museográfico y el montaje de la colección. Para esto se considerada las medidas necesarias para la buena conservación de las obras y su seguridad.

- Rediseño museológico-museográfico del Museo de Arte Religioso "Fray Pedro Gocial" e implementación de nuevas salas de exposición

Dado que actualmente las vitrinas y el montaje de varias obras no facilita las actividades de conservación preventiva, y las pone en riesgo al momento de ejecutarlas. Que varias obras se encuentran en condiciones de no seguir en exposición y que la riqueza de la colección puede permitir abordar la temática del arte religioso desde otras perspectivas se plantea un rediseño museológico-museográfico.

Este nuevo planteamiento museográfico deberá ofrecer "las relaciones adecuadas con relación al espacio físico, al mobiliario, al montaje, a las condiciones ambientales y al mantenimiento" (Matiz \& Ovalle, 2006).

Se propone también la ampliación de la temática del museo a la parte arqueológica y costumbrista de la vida monacal en el convento. Siendo la inclusión de la sala temática de la cerveza franciscana el inicio, con el objetivo de diversificar la oferta del museo y poder crear varios recorridos para públicos con intereses distintos al arte religioso.

\section{Principales acciones emprendidas para la conservación del patrimonio mueble}

Con base en las líneas de acción propuestas y al nivel de prioridad de ejecución de las acciones de intervención, se emprendieron dos proyectos importantes en el marco del Plan de Gestión. Estos fueron: "Estudio analítico e intervención de conservación en la colección de pintura de caballete de la Vida de San Francisco de Asís" y "Conservación de indumentaria y ornamentos religiosos", ambos proyectos ejecutados en su primera fase y que han marcado el inicio de las acciones de conservación en conjunto con la Universidad Tecnológica Equi- 
noccial UTE ${ }^{193}$, sumándose la Escuela Nacional de Conservación, Restauración y Museografía "Manuel del Castillo Negrete" (ENCRyM), de México, en el primer proyecto. En las diferentes acciones desarrolladas las instituciones parte del Plan de Gestión, han colaborado de acuerdo a sus posibilidades de equipos, personal y otros recursos disponibles.

\section{Estudio analítico e intervención de conservación en la colección de pintura de caballete de La Vida de San Francisco de Asís - 1era fase}

La serie de la Vida de San Francisco es una de las más representativas para el convento, al versar sobre su santo patrono. Actualmente está conformada por 27 cuadros que se ubican en distintas áreas del convento. Por estas características y la prioridad en intervención fue uno de los primeros proyectos ejecutados, para lo cual se trabajó en colaboración entre la UTE con su carrera de Restauración y Museología y el ENCRyM ${ }^{194}$, que tuvo como objetivo minimizar los deterioros que presentaban 3 obras de la colección, estabilizarlas estructuralmente y propiciar el intercambio de conocimientos y experiencias entre pares.

La intervención partió de un diagnóstico previo en conjunto con los análisis de laboratorio a cargo del INPC, información que permitió delinear una propuesta de intervención, la cual fue debatida en conjunto con las dos escuelas y presentada públicamente el jueves 06 de noviembre en la UTE, con la concurrencia de profesionales del medio y estudiantes de la Escuela de Restauración y Museología. Durante la intervención ${ }^{195}$ en las obras se realizó su limpieza superficial, desmontaje, fijado de la capa pictórica, eliminación de elementos añadidos, tratamiento de roturas, velado y corrección del plano.

Con esta colaboración académica de carácter nacional como internacional, se marcó el inicio de una posible colaboración sostenida con el ENCRyM y otras de instituciones del ámbito de la conservación de diferentes países, para posicionar al Conjunto Conventual como un centro de investigación del patrimonio cultural en marco de su Plan de Gestión.

\section{Conservación de indumentaria y ornamentos religiosos - 1era fase}

La primera fase ${ }^{196}$ comprendió el traslado, diagnóstico y conservación ${ }^{197}$ de cerca de 54 ornamentos religiosos entre: estolas, manípulos, casullas y cuadrantes, y la restauración de dos casullas. La ejecución de estas actividades estuvo a

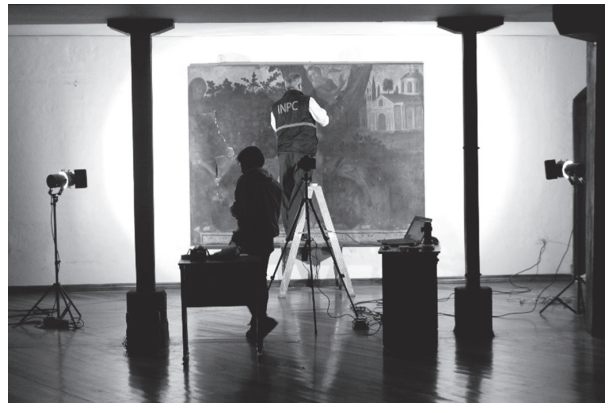

Foto 2. Toma de muestras en base al análisis multiespectral de una obra de la Vida de San Francisco por parte del equipo del laboratorio del INPC. Fuente: Autor

193 El convenio de colaboración entre las instituciones integrantes del Plan de Gestión y la UTE se firmó el 09 de septiembre de 2013, con una vigencia de 5 años.

194 Su estancia en el país se hizo posible gracias a la apoyo del Ministerio de Cultura y Patrimonio del Ecuador y la Embajada de México en el Ecuador.

195 La misma inició el 02 de noviembre y se prolongó hasta la primera semana de diciembre de 2013.

196 La intervención se inició la primera semana de diciembre de 2014 y culmino el 31 de marzo del siguiente año.

197 En líneas generales la intervención de conservación comprendió: la limpieza superficial, colocación de puntadas provisionales y de restauración, sujeción de ornamentos y colocación de elementos temporales. 
cargo de la UTE, mediante docentes y estudiantes de su Escuela de Restauración y Museología.

Como estrategia de difusión y de acercamiento a la comunidad se decidió que el taller de conservación sea visitable, para aproximar a los visitantes del Museo Fray Pedro Gocial, del Convento y a la Comunidad Franciscana a las tareas de conservación, que conozcan sobre las técnicas de manufactura y que puedan observarlos de cerca.

Para continuar esta labor emprendida con un taller abierto, se planteó montar una exposición de carácter temporal que comprende un recorrido por las principales técnicas de manufactura de la indumentaria religiosa, usada para la celebración de la liturgia por los padres franciscanos en el siglo XVII hasta inicios del XX.

Esta exposición ${ }^{198}$ se denominó "Del bordado al significado: indumentaria religiosa", y comprendió la muestra de prendas que fueron bordadas por hilos seda, algodón y metálicos, con diseños florales e imágenes cargadas de simbolismo. Estas prendas de fabricación local y europea, comprendieron: casullas, bolsa de corporales, dalmáticas, estolas, manípulos y albas.

El haber partido de tener un taller de conservación que sea visitable, en una determinada hora del día, visitas guiadas los días sábados y posteriormente una exposición, hizo necesario que se plantee un recurso educativo para permitir que los todos los visitantes puedan tener un acercamiento al patrimonio que sea gratificante y de larga duración, estas necesidades dieron paso a la campaña "Pinto por el Patrimonio de San Francisco", la cual por

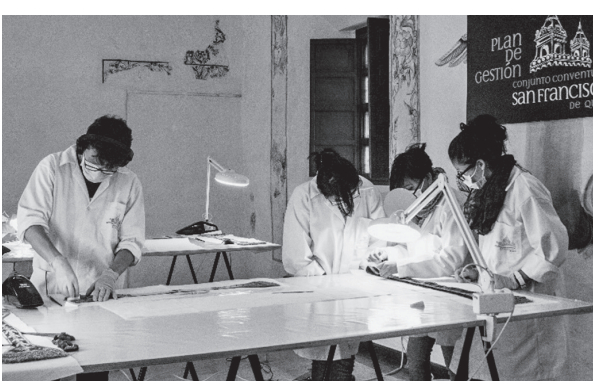

Foto 3. Trabajo ejecutado en el taller de conservación de textiles por estudiantes de la UTE. Fuente: Autor su importancia la detallamos a continuación.

\section{Pinto por el patrimonio de San Francisco: una experiencia de acer- camiento a la comunidad ${ }^{199}$}

Con la idea de mantener una continuidad en este proceso emprendido, se propuso realizar una exposición con los ornamentos religiosos, la cual fue pensada como un medio de comunicación, un escenario y un recurso de aprendizaje (Ochoa, 2008), ideas acorde a la definición actual de Museo del ICOM ${ }^{200}$ : “el museo es una institución sin fines de lucro abierta al público y al servicio de la sociedad, que adquiere, conserva, investiga, comunica y exhibe, con el propósito de

198 La exposición se inauguró el 24 de abril y se clausuro el 31 de mayo de 2015.

199 Extracto de la ponencia "Pinto por el patrimonio: una experiencia de educación no formal", presentada por el autor en el "I Congreso Internacional Compartiendo Experiencias Educativas Innovadoras", desarrollado en Quito del 23 al 25 de septiembre de 2015 (Zambrano, 2015). 
educación y deleite" (Alderoqui \& Perdesoli, 2011). Bajo esta premisa, los museos se constituyen como espacios de educación no formal que buscan atender a las necesidades educativas particulares de cada visitante (Zavala, 2006).

A fin de crear un vínculo entre el visitante y el patrimonio cultural del convento de San Francisco y a la vez ir respondiendo a las necesidades particulares de los visitantes, se pensó en implementar un "servicio educativo" que favorezca la comprensión y mejore la interpretación o asimilación del tema de la exposición (Ochoa, 2008), naciendo así la propuesta Pinto por el Patrimonio de San Francisco".

\section{Construyendo la propuesta}

Al hablar de patrimonio ${ }^{201}$ en Quito, muchas veces se refiere a su Centro Histórico, si bien el mismo se mantiene como un espacio de orgullo, de memoria e identidad (IMP, 2013), hoy nuevos espacios tienen una valoración de carácter patrimonial para la gente ${ }^{202}$.

En el caso de San Francisco su Iglesia se reconoce como parte importante del patrimonio histórico, pero esto no sucede con el museo y su espacio conventual los cuales son desconocidos por la mayoría de quiteños, imposibilitándose así crear experiencias memorables de aprendizaje y compromiso emocional, que permitan convertir a la visita en un lazo emocional de carácter intercultural e intergeneracional (Zavala, 2006).

Conscientes de este contexto, la exposición denominada "Del bordado al significado: indumentaria religiosa ${ }^{203}$ ", fue pensada como una experiencia educativa independiente de la educación formal y conscientes de que cada visita implica múltiples objetivos y experiencias concretas, la propuesta buscó incentivar un diálogo entre el contexto del visitante y la experiencia de visita (Zavala, 2006).

Como apoyo a la experiencia educativa per se de la exposición, se fue construyendo la campaña Pinto por el patrimonio, la cual tomo como recurso las artes plásticas, las mismas que permiten desarrollar una experiencia lúdica con el público, sin importar su edad o nivel de destreza, y por la relación con la Escuela de Artes y Oficios San Andrés, la cual funciono a partir del siglo XVI en el convento de San Francisco.

Para la campaña, como su nombre lo indica, se escogió como recurso la pintura, los diseños a ser coloreados fueron tomados de los ornamentos a ser expuestos, buscándose que los mismos sean florales o geométricos, a fín de que la propuesta sea pluralista y no tengan una carga religiosa. Los bocetos, en un número de cuatro, fueron reproducidos en cartulinas, llevando como leyenda el

201 Es decir pensando en lo arquitectónico, artístico e histórico.

202 En la campaña “Cuéntame tu Quito”, liderada por el Instituto Metropolitano de Patrimonio (2013), el cual buscó fomentar la reflexión ciudadana sobre la idea de patrimonio, se mencionan como nuevos patrimonios a espacios recreativos, balnearios, centros comerciales, restaurantes, bulevares, estadios y coliseos, transporte y mercados. Esto es entendible porque son sitios o servicios que hoy forman parte de su cotidianidad, y se han convertido en lugares donde se desarrollan eventos significativos de su vida.

203 La exposición estuvo ubicada en la sala de exposiciones temporales del Museo Franciscano "Fray Pedro Gocial", y permaneció abierta al público desde el 24 de abril al 31 de mayo de 2015. 
ornamento al cual pertenecían y su época de realización. El espacio escogido para desarrollar la actividad fueron los corredores del convento, dado su amplitud y la tranquilidad que existe en los mismos.

Con la propuesta armada se inició la campaña de difusión, para llegar a más personas se recurrió a las redes sociales y a la difusión entre las personas que nos habían visitado antes en el taller o habían ayudado en otras fases del plan de gestión. Se buscó la participación en familia y sin límite de edad, ya que se esperaba que la participación de personas de diferentes edades se convierta en una fortaleza, al trabajar complementariamente en la actividad.

\section{La experiencia}

Las familias, amigos y visitantes asistentes a la campaña Pinto por el patrimonio, iniciaban la misma recorriendo la exposición con la mediación de voluntarios, que anteriormente habían participado en la intervención de los ornamentos religiosos, haciendo de la visita un oportunidad para exponer su experiencia. Esto ayudó a que muchas de las personas puedan ver contestadas sus interrogantes, especialmente las de carácter técnico. El público fue instado a ver la exposición minuciosamente, la cual tenía como recurso museográfico, cerca de 18 fotografías macro de áreas decorativas y de manufactura, que buscaban replicar la experiencia mantenida durante la visita al taller, donde había observado, a través de una lupa de gran aumento, los detalles de los ornamentos, causando gran sorpresa en los asistentes al conocer de cerca los diferentes bordados.

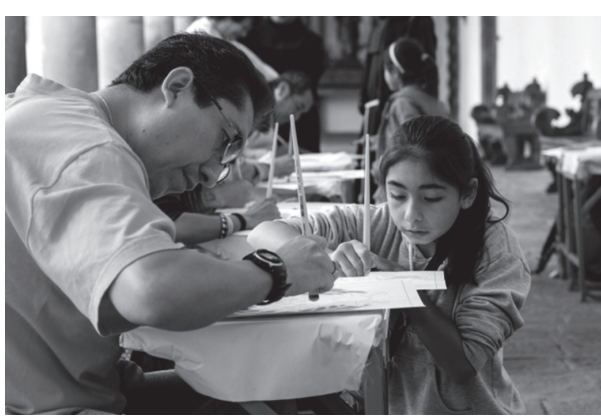

Foto 4. Pequeños y grandes pintando por el patrimonio. Fuente: Autor

Al concluir la visita y asistir a una función

de títeres donde se contaba sobre la leyenda de Cantuña y la cual tenía como fin, además de conocer sobre la leyenda, permitir una integración en el grupo, se procedía a pintar los diseños, los cuales se entregaban de acuerdo a la edad, ya que tenían diferentes grados de dificultad, esto no impedía que si alguien quería pintar otro diseño, lo haga. Durante la actividad se les pedía pintar libremente los diseños, interpretando y resignificando los mismos de acuerdo a cada persona. Al concluir, los autores ponías su firma en la pintura, demostrando satisfacción por su trabajo, otros tenían preguntas sobre los ornamentos religiosos, entre las preguntas que se generaban predominaban: cuál es color, su forma, en qué parte se ubicaban, cuál era la fecha de realización, o simplemente querían volver a ver la exposición y en muchos casos, tomarse una foto con su obra junto al objeto expuesto.

Finalmente cada pequeño o gran artista, por su edad más no por asignar un grado de calidad a su obra, era fotografiado con su trabajo para integrar la galería de participantes de la campaña y era compartida en las redes sociales para que los asistentes tengan un recuerdo adicional a su dibujo pintado y también para motivar a más personas a participar. 

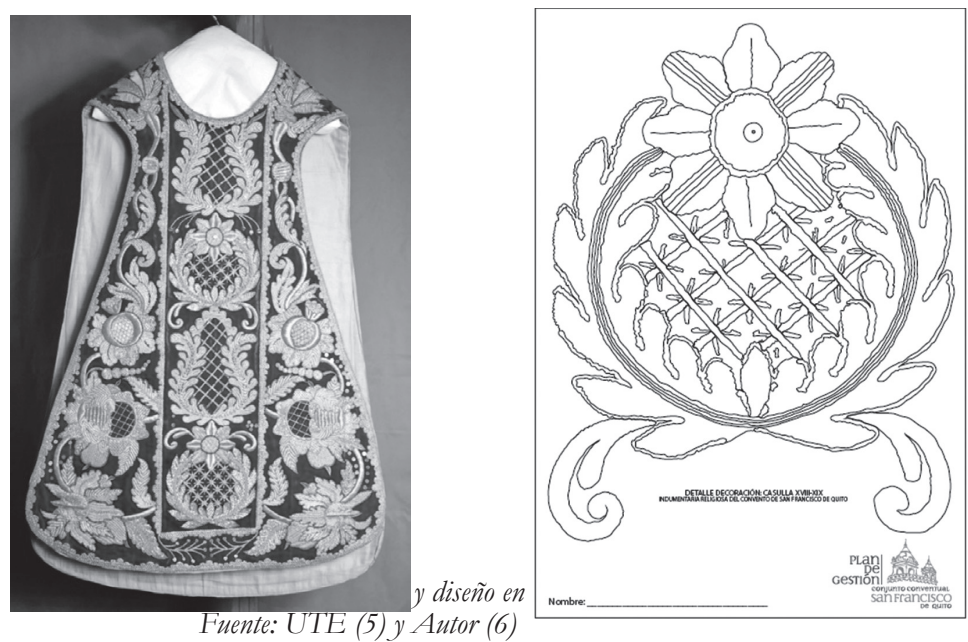

\section{Conclusiones}

El conjunto conventual de San Francisco dada su extinción y el número elevado de bienes muebles, ha demandado que en su propuesta de gestión, la conservación sea asumida por varios socios estratégicos y se vaya delineando acciones en conjunto. Para la eficaz implantación y sostenibilidad del mismo es necesario repasar estos acuerdos de colaboración.

Uno de los principales factores de deterioro, contrario a lo que se pensaría, son las acciones del humano, ya sea por una utilización no cuidadosa de los bienes muebles que aún se encuentran en uso religioso, como es el caso de los albergados en la Iglesia y Capilla de Cantuña. O por acciones vandálicas que han producido entre otros deterioros: fracturas, desprendimiento de estratos, marcas, rayones y quemaduras

Los elementos que se pueden considerar como patrimoniales desde una visión tradicional, no adquieren ese grado, hasta que son portadores de una significación para cada persona. Son los museos con sus exposiciones y sus servicios educativos, el medio ideal para propiciar esta interacción. En muchos casos el círculo de

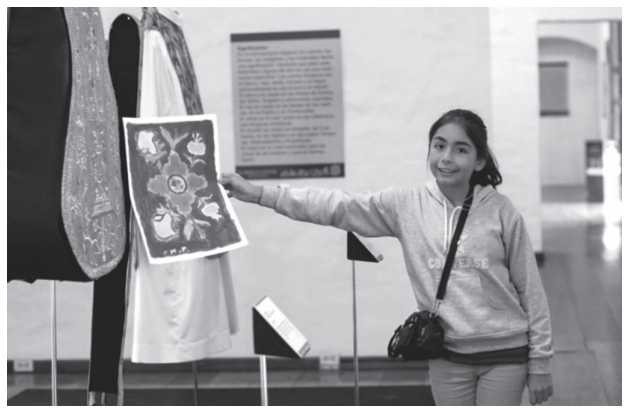

Foto 7. Participante en la campaña Pinto por el patrimonio de San Francisco junto al ornamento religioso del cual se extrajo el diseño. Fuente: Autor aprendizaje se realiza bajo las necesidades e inquietudes de cada persona, pudiéndose dar hasta en varios años después de la visita de la persona al museo, al tener como elemento propiciatorio, un dibujo pintado, una foto, un recuerdo, que actúa

comp catalizador de preguntas.
Bibliografia

Alderoqui, S., \& Perdesoli, C. (2011). La educación en museos: de los objetos a los visitantes. Buenos Aires: Paidós. 
IMP. (2013). Cuéntame tu Quito, memoria, saberes y patrimonio. Quito: IMP.

INPC. (03 de Diciembre de 2015). Convento de San Francisco después del terremoto de 1868. Quito - Pichincha - Ecuador. Obtenido de Archivo Nacional de Fotografía: http://www.fotografianacional.gob.ec/web/app.php/es/galeria/ element/5538

IPCE. (2011). Plan Nacional de Conservación Preventiva. Madrid: IPCE.

Matiz, P., \& Ovalle, B. (2006). Conservación preventiva en museos: evaluación de riesgos. Bogotá: Universidad Externado de Colombia.

Moreno, A. (1998). Fray Jodoco Rique y Fray Pedro Gocial. Apóstoles y Maestros franciscanos de Quito 1535-1570. Quito: Abya-Yala.

Navarro, G. (2006). La escultura en el Ecuador durante los siglos XVI, XVII y XVIII. Quito: Trama Ediciones.

Ochoa, L. (2008). Los museos: espacios para la educación de personas jóvenes y adultas. Decision, 3-13.

UNESCO. (2013). Plan de Gestión para el Conjunto Conventual de San Francisco de Quito. Quito: Documento inédito.

Zambrano, I. (2015). Pinto por el patrimonio: una experiencia de educación no formal. Quito: Documento inédito.

Zavala, L. (2006). El paradigma emergente en educación y museos. Opción, 128141. 